\title{
LIBRARIES RE-LOADED IN SERVICE OF THE MARGINALIZED
}

\author{
Juliano M. Kabamba
}

\begin{abstract}
Attainment of the Millennium Development Goals (MDGs) is a high priority development initiative of the United Nations and the concerned national governments in partnership with the international community. However, the responsibility to meet specific MDGs includes numerous players. Public libraries are expected to play a critical role given their strategic position to impact on ordinary lives in the communities in which they operate.
\end{abstract}

In most countries in Sub Sahara Africa the profiles of public libraries leave much to be desired. Funding bodies struggle to justify requests for more investments in public libraries while the larger population; the intended beneficiaries, generally find public libraries irrelevant to improving their socio economic circumstances.

The concept of a public library is essentially Eurocentric and elitist. The way public libraries are structured and function tells a story of institutions that are engineered to serve a relatively more educated and technologically sophisticated population. By and large public libraries are a luxury of the working class and the schooling society. As such people at the lower stratum of society; the poor, illiterates, unemployed and rural communities are primarily excluded. And yet it is the underprivileged and the marginalized that we should be targeting if public libraries are to be seen to be playing a meaningful role in national building in general and the realization of the MDGs, in particular.

Why are public libraries failing to meet information needs of the social groups that are less privileged? Why should it be that information needs of the poor are still unfulfilled many years after independence?

This paper is intended to identify basic flaws in the governing principles and functionalities of public libraries. More importantly the paper contends that there is need for a complete overhaul of public libraries in Africa. This will be necessary to arrive at a more inclusive and relevant community development information system: An information system that will be uniquely African and one 
that will help to advance the mission of the Millennium Development Goals to alleviate poverty and mitigate the suffering of the African people.

Keywords: Public libraries in Africa, Resource Centers, Information services, Community development, Development information, Millennium Development Goals

\subsection{Introduction}

From inception the journey of public libraries in Africa has been very bumpy for reasons well documented in literature. Some of the key issues are discussed. The main thrust of this article is that public libraries as we know them today have failed the cause of the majority of Africans who are disadvantaged and marginalised. A radical shift to the general principles underpinning public library practice is proposed to give way to a recipe of an 'African public library': A model which is essentially based on relationship building and networking.

\subsection{Millennium Development Goals}

The United Nation member states adopted the Millennium Declaration and the Millennium Development Goals (MDGs) in 2002. The goals have since become a universal measure of development and a basis upon which developing countries can work together with development partners to fight poverty and improve the socio-economic circumstances. The majority of MDGs targets have a baseline of 1990 and a target date of 2015.

Half way down the line progress was reported (UN, 2007) in a number of areas but many challenges were also identified. For example in one of the primary goals it was noted that "The number of extreme poor people in sub-Sahara Africa has leveled off, and the poverty rate declined by nearly six percentage points since 2000. Nevertheless, the region is not on track to reach the goal of reducing poverty by half by $2015 "$ (UN, 2007:4).

There are many factors that could contribute to achieving millennium goals. At national level one can single out economic growth, public investments and good governance as fundamental. Needless to mention that national effort alone may not be sufficient to meet the challenge. It is expected that the international development partners will rise to the occasion to honour their commitments to scale up national investments. 
Having stated that it must be empasised that the responsibility to attain the MDGs does not only lie in the ambit of national governments and global development partners. It is an imperative that extends to a large body of organisations including provincial and local governments, municipalities, private entities and civil society. Public libraries, in whatever domain they might fall, are expected to play a critical role to support the attainment of the millennium goals.

\subsection{Public good of Public Libraries}

According to the IFLA/UNESCO Public Library Manifesto a public library is a "gateway to knowledge" which should provides "...basic condition for lifelong learning, independent decision-making and culture development of the individual and social groups"(IFLA, 2004). The manifesto highlights the mission of public libraries to foster information literacy, education and culture and looks at a public library as a vehicle for peace, development and spiritual growth.

One remarkable attribute of a public library is that it is expected to open its doors to all and on equal basis without prejudice to race, gender, religion, education, language, sex or social status. In this light a public library could be seen as a 'public good'; a social investment that prepares society for citizenship, democracy and development.

\subsection{Libraries for fun}

The purpose of public libraries, and their uses, has been an arena of curious contestations for many years. The globally acclaimed public good of public libraries, as agents of citizenship and development, often contradicts the pattern of use.

As early as $19^{\text {th }}$ century library circulations statistics in the United States leaned more in favour of popular fiction (Akst, 2005) at the expense of educational materials. This provoked a raging debate on how to confront the overwhelming demand for fiction. Some libraries responded by scaling down on fiction holdings and one library in Pennsylvania took a more drastic decision by deciding to completely cut out fiction literature. It was only at the turn of the twentieth century that it dawn on many public library authorities that "the public preference for books of little or no educational value was an enduring one” (Akst, 2005).

Subsequently, in 1947, the Carnegie Foundation commissioned a large scale study of public libraries (Akst, 2005). The primary focus of the study was the 
purpose of public libraries. This study once more validated earlier observations about the preponderance of reading for leisure. The study, commonly referred to as the Public Library Enquiry, noted that much of public libraries use was recreational. "Most was fiction, most reference questions were simple, and most of the users, rather than proletarian hungry for knowledge, were comfortable middle class." (Akst, 2005).

The debate has continued to the present. With the advent of the Internet a new era has been ushered in. Public libraries are increasingly used as centres for ebased communication and information transfer. And of course a large portion of it is all for entertainment.

\subsection{Study space rules}

Africa offers an interesting point of contrast to the United States experience. School children have invaded public libraries in large numbers. The adult population is in the minority (Issak, 2000). The influx of the school going population in public libraries does not necessarily mean that public libraries are well stocked with school textbooks or curriculum based learning materials. Neither does it imply that children and young adults are more conscious and appreciative of the wealth of knowledge and information to be found in public libraries.

What appears to be the case is that school children are being attracted by the public space available for study purposes. In a research paper on information needs for poverty alleviation in urban poor communities (Mchombu, 2007:11) it is noted that adults and learners identified an existing community information centre as crucial to support education given that most homes in the community were 'too small' and did not have electricity, study tables and chairs. By and large school children find public libraries as convenient places for study; to complete their 'home work' and prepare for class tests and examinations.

\subsection{Creating opportunities}

Why should public libraries take centre stage to address the challenges of the Millennium Development Goals?

Seemingly the cardinal manifestation of underdevelopment in Africa is extreme poverty. It is therefore not surprising that eradication of poverty stands out as the key challenge to attainment of the millennium goals. 
Poverty is a humiliation to human civilization. It disrupts the entire fabric of human existence; culture, norms and traditional practices. It deprives people of choices and exposes them to the bondage of ignorance, diseases, insecurity, exploitation and discrimination. For these reasons public libraries will be well advised to embrace human development as a philosophical basis for advocacy and for programme of action.

Human development is not so much about the wealth of a nation but setting a foundation upon which society can create opportunities to improve social and economic conditions. According to UNDP (2007/8) human development borders on creating a platform that will assist people to realize their full potential and lead productive lives as they deem fit. In this respect human development can be described as a process of empowerment that will enable individual members of a community to access food, health, shelter, sanitation, education and other value adding attributes of modern life.

If empowerment is so crucial to fight poverty then access to information becomes the most powerful driver to make the disempowered become aware of options and opportunities that may lie ahead of them. It is generally acknowledged that knowledge is at the centre of development (World Bank, 1999). This places libraries in a very strong position to fast track attainment of the millennium goals.

\subsection{Colonial legacy}

Perhaps the most fundamental challenge facing public libraries in sub-Sahara Africa is the question of identity and relevance (Kabamba, 1999). It is not unusual to see a public library in an urban area however library services provided are essentially alienated from the communities they are intended to serve. Literature is abounding with evidence suggesting that there has been an underlying mismatch between the ideology, structures and activities of public libraries on one hand and the aspirations of the African people on the other.

It is common knowledge that Africa adopted public library models based on Anglo-American systems (Hart, 2007). Many pioneer librarians of independent Africa received library education overseas in countries such as the United States and the United Kingdom. The library education received was hardly appropriate to material conditions in Africa (Mostert, 2001). Similarly the curriculums of library schools that were opened in Africa were also influenced by imported library models that had little or no bearing to the political and social-economic situation prevailing in Africa (Issak, 2000). 
In the same spirit public library products and services have also failed to find expression in the information needs and wants of the African masses. Depending largely on printed matter, acquired from colonial masters and other economically advanced countries, public libraries have, at best, appealed to the marginal information interests of the educated. Thereby leaving the information needs of the vast majority of the semiliterate, illiterate and underprivileged populations unfulfilled (Alemna, 1995).

The organization of public libraries into compartments that are better understood by librarians would not make an average man, with little or less education, feel welcomed. On the other hand the restrictive rules and regulations, coupled with penalties for noncompliance, could actually serve as a barrier to access public library services (Brain, 2005).

\subsection{Compounding factors}

The reality is that even Africans who are considered to be more enlightened in western languages and knowledge systems are not adequately catered for by public libraries. Most public libraries are chronically under resourced. Undue reliance on book donations, deployment of untrained staff to provide services and lack of capacity to analyse information needs have not helped the cause of public libraries in Africa (Dent \& Yannotta, 2005). Economic hardships confronting many African countries and inability of governments to recognize the significance of libraries have made conditions far worse for public libraries whose existence largely hinges on government subventions. It is noted that "In the majority of cases, the government guarantees only payment of salaries and does note finance any activity within the sector" (Issak, 2002:12).

Many other factors have contributed to the current state of public libraries in Africa. Among such factors are the high costs of reading materials, weak local publishing industry, illiteracy, inadequate literature in indigenous languages and scarcity of materials that represents the 'world view' of Africans. For example, in the Western Cape; one of the more wealthy provinces of South Africa, one study notes that there were less than $1 \%$ of publications in indigenous languages in public libraries sampled (Ocholla, 2006). This is a dismal performance for the richest country in Africa that is constitutionally obliged to promote access to information in all eleven official languages that include ten indigenous African languages. 


\subsection{Library groupies}

In general the reach of public libraries in Africa in terms of people served is unimpressive to say the least. Statistics on pattern of use of public libraries, in proportion to the intended user community, are hard to come by in literature. However there is sufficient evidence to suggest that public library services have very little meaning to communities they purport to serve. Mchombu (Mostert, 1998) writes that "Less than $2 \%$ of the population in Tanzania and approximately $5 \%$ in Botswana use libraries". Citing a UNESCO source on the number of users of public libraries in Uganda in 1992, it is observed that “... only 53,000 registered library users out of a population of over 20 million" (Dent, 2005:39). This represented a negligible $0.3 \%$ of the total population. South Africa; a country believed to have the most sophisticated public library system in Africa (Lor, Helden \& Bothma. 2005:268) only attracts less than 10\% of the population (Hart, 2007:15). In contrast a poll conducted in 2002 for the American Library Association noted that $62 \%$ of the adult populations were reported to be registered members of public libraries (Akst, 2005).

\subsection{Alternative Information Services}

The Library Association (Alemna, 1995) defines community libraries as "Services which assist individual and group with daily problem solving and with participation in the democratic process. The service concentrates on the needs of those who do not have ready access to other sources of assistance and on the most important problems people have to face, problems to do with their homes, jobs, and their rights".

Community libraries are more attuned to the needs of the disadvantaged or socially excluded populations than public libraries. One description of the disadvantaged population that comes to mind defines them as "Those who are disabled, mentally ill, addictive, less educated, less literate, less able to speak English, Those who have left school, have become parents early or have experienced or perpetrated violence. And many more" (Darla, 2005:265). To this list one could add the army of the unemployed and a large constituency of Africans who are struggling to make their living in the informal sector of the economy.

Community libraries are not normally funded by government. They are generally created by/for local communities under development aid or resources generated through community based initiatives. What is unique about community li- 
braries is the idea of local communities taking responsibility for their own information and development needs.

Literature points to a variety of community libraries in Africa. For example we have Village Reading Rooms in Botswana and bare-foot librarians in Tanzania (Mostert \& Vermeulen, 1998), (Dent, 2005:40). The Kitengesa Community Library in Uganda is another example (Dent \&Yannotta, 2005), (Dent, 2006).

Nevertheless, in the main, community libraries on the African continent have not succeeded to cement their initial gains and develop into formidable broad based vehicles to uplift local communities and help alleviate poverty. Many reasons could be cited ranging from planning to communication and poor collaboration with community stakeholders to lack of skills for proper analysis and interpretation of community information needs. Donor support was one important ingredient that accounted for the early successes of many alternative information services. It provided the much needed momentum however the decline of donor support marked the beginning of their demise.

\subsection{The telecentres option}

In an effort to establish a pipeline for information flow and empower the disadvantaged rural communities the South Africa government experimented on yet another approach involving setting up ICT centres in townships and rural areas. This was a response to confront the growing digital divide and make telecommunication technologies available to enable local communities to access information for social and economic development. In essence telecentres were geared to provide government information, telephone lines, internet, photocopying, fax, and even word-processing facilities at nominal fees.

Snyman and Snyman (2003) elaborate on the evolution of telecentres pointing out the difficulties encountered to live up to the expectations of government. Despite the good intensions telecentres failed to attract local communities as mainstream sources of information and communication conduits for the poor. Primarily the clientele base was confined to school children who often frequented the centres especially during school holidays. The critical mass of the rural dwellers and the marginalised; the intended beneficiaries of the project did not catch the fever.

It is observed (Snyman \& Snyman) that from the onset telecentre were riddled with numerous operational problems including poor financial systems, lack of 
training of telecentre managers, security of equipment, technical problems with telephone lines and high costs of communication. According to the analysis of Snyman \& Snyman (2003:105) the telecentre project did not bear desired fruits for three fundamental reasons: The unproven assumption that ICT can provide solutions to all social problems, greater attention to technology at the expense of human and social capital and the top-down approach to development.

\subsection{Transforming the landscape}

From the aforementioned discussion public libraries in Africa have not made significant inroads to fight poverty. The birth of alternative information services was heralded as a great relief to the socially excluded and the marginalized. However, continued success has been illusive.

Librarians should not look elsewhere but themselves to place public libraries on the development agenda. Rather than establishing parallel or alternative information services, what is envisaged is a bold move to completely overhaul public libraries. A new approach will entail bringing down the 'brick walls' of public libraries and starting anew, block by block!

\subsection{Rethinking library philosophy}

The tragedy of public library practice for many years has been that library authority and their cohorts; librarians, have colluded to provide the public what they think the public needs rather than what the public wants. Preoccupation with the broader values of the 'public good' of public libraries to the detriment of practical information needs and desires of the target library community is at the core of the inability of public libraries to win public confidence and support.

Lor, Helden and Bothma (2005:268) argue that libraries are not 'ideologically neutral.' Dick (Hart, 2007:15) comes out strongly to refer to the '...naivete of South African Librarians who, he claims, operate unconsciously from within a positivity paradigm and so see libraries as objective neutral reality isolated from their political and economic contexts.' One would imagine that this assertion might well be true of a larger segment of librarians on the African continent

Public libraries can not be everything for everybody irrespective of the political, economic and social circumstances. The stakes are too high! Not when the scorch of poverty continues to ravage the continent and there is a growing sense of disempowerment, disillusionment and hopelessness among the African 
masses. Public libraries need to break away from this fallacy and touch base with reality. Public libraries should make informed choices about the nature of their transactions and engagements based on actual needs and not assumptions or common ideals. A public library should embody and mirror the hopes and dreams of the community it serves. Only then will it begin to win the acknowledgement and respect of the local population and broader society.

\subsection{The fear factor}

Why should public librarians be contended with a service that brings shame to the profession? It will be inconceivable to believe that librarians are not aware that they are off target in meeting the information needs of the needy and bigger portion of the population. Librarians do not hail from outer space. They are part and parcel of the communities they serve. More often than not they share the same neighbourhood with the intended beneficiaries of public library services and talk to some members of the community, from time to time, as friends, relatives, members of a church congregation or a 'community of practice' etc. As such librarians are, by and large, informed of the actual needs of the communities they purport to serve.

Is the reluctance to change borne out of stubbornness or professional arrogance or are librarians waiting for clues from library authorities and funding bodies? The message is clear. When library funders say that 'we are tired of pouring money in a bottomless pit' they are actually saying 'guys is this all you can do with all the resources we plough in your activities?' At another level it seems apparent that librarians in Africa are so obsessed and mesmerized by the AngloAmerican standards and feel so contracted to their specifications that they are not inclined to consider other options even if common wisdom compels them to do so. They religiously cling to the blinded pledge to uphold 'professional status' when the situation on the ground is calling upon them to listen, and respond, to the plight of the disadvantaged communities.

\subsection{In-house renovations}

The public library, as an institution, has to be remade to be more accommodating to the disadvantaged populations. Currently it has all the trappings of elitism and bureaucracy. Public libraries are structured and organized to appeal to the appetite of the more educated populations. Library rules and the behavioral pattern that they promote depict the library as an organised and controlled environment (Brian, 2005). A semi literate, let alone an illiterate African, might feel 
intimidated by the establishment. There is need to liberate the public space in libraries by abandoning the authoritative, formal and instructive cultures and move towards more flexible, more inclusive and more tolerant practices that will comply with the ethos of the local communities.

\subsection{Knowing your boss}

It is true that library authorities, be it at provincial or local government levels, ultimately decide on resource allocations for public libraries and are pay masters of librarians. It is also correct to state that library communities; both actual and potential beneficiaries, are the most important stakeholders in determining the nature of resources and activities of public libraries. Librarians should always be conscious of the political leverage that library communities wield as tax payers and people who will carry the vote in contests for political offices. A continuous dialog and alliance between librarians and community group leaders can be a potent rallying point for public library advocacy.

\subsection{Courtship and networking}

There is simply no substitute for needs analysis in determining information needs of local communities and yet not many public libraries will attest to the practice on a regular basis. Mostert (2001) emphasises the need to gauge information needs of the actual and potential audience. Ocholla (2006) laments the inability of libraries to reach out to the marginalized. He singles out poor 'design' of libraries and lack of sensitivity to the information needs and information seeking behaviours of the underprivileged, as missing links. In the same vein Mchombu (2007) argues that one of the prerequisites to eradication of illiteracy and poverty is identification of 'information gaps' and repackaging of information.

The method used for identification of information needs is of utmost importance. A community based approach is commended. This approach does not start with a product or library collection. It starts with relationship building between librarians and the local community. In relationship building librarians will begin to understand and appreciate the social and economic circumstances of the target audience. Relationship building does not happen overnight. It can be a painfully slow experience in which the librarian takes time to listen to the stories of grass root organizations, development agencies, religious, literacy, funeral societies and similar groupings that may exist in the community (Kabamba, 1999). 
In relationship building a librarian could pay regular visits to a site, or several locations, of existing community development projects as a guest to seek understanding of the burning issues or intricacies of development initiatives. A librarian can also invite community group leaders to meet at the public library to share information on issues of importance to the community groups they represent. Such visits, if approached with sincerity and consistency, could help to reduce the social distance between libraries and the communities they are supposed to serve.

The main idea here is to connect with the local population in their own comfort zones, win their trust and create a non threatening channel to articulate their needs. These interactions can also assist the librarian to develop community profiles detailing existing community groups, their contacts, missions and activities. The mapping of stakeholders could be an asset to identify priority information needs of various interest groups in the community.

\subsection{Harvesting stories}

Relationship building will be augmented by small to medium scale needs assessment surveys. Caution must be exercised in conducting surveys and interpretation of results. Disadvantaged communities are not traditional library users, neither will they be comfortable with filling questionnaires. Socially excluded community members may not cooperate to answer questions or attend meetings as they have 'more important issues to worry about'. For many such people every day that comes is totally committed to a perpetual vicious circle of struggle for survival. However, a sustained cordial relationship between the librarian and the community, based on respect and trust and the networks that evolve as a result, can help in facilitating conversations and bonding.

Many public libraries do not have the capacity for conducting systematic needs assessment surveys. It is understandable that not all librarians will poses these skills. There are other people and organizations that can work with public libraries, to either develop skills or do the job on their behalf. Library schools, in particular, can provide support. Library associations and some development agencies can also be approached for professional guidance, material support or to commission studies. Librarians should be mindful that statistics alone may not give sufficient information or desired results. Sometimes quantitative data can even be misleading. As Brain (2005) points out "While most library services are justified quantitatively, working with the community is measured in charging lives and gathering stories." 


\subsection{Service level agreement}

Information gathered by listening to 'stories' of community members, community maps and surveys will form a firm basis for setting up library services that are pertinent to the real and current information and development needs of the community.

If such information suggests a need for a child day care, book talk, story telling, life skills, indigenous art exhibition, crafts, drama, career guidance, literacy facilities etc, the library has to give serious consideration to those needs. If there is compelling evidence that a representative group of a community is in dire need of current information on employment prospects in the community, counseling services, HIV/Aids related information, or second hand dealership then the library has to give attention to how best such information can be sourced and disseminated. Similarly if a significant proportion of the community is interested in what is happening in the community or nation the library will give some thought to provision of current information in news papers, radio, or television, whatever will be appropriate.

A library does not need to have expertise in all these areas of need. In fact it will be unrealistic to expect a librarian to have sufficient knowledge in all sectors of need such as listed above. Nevertheless, in a networked environment, referred to above, the librarian will rely on the community maps and personal contacts to identify 'local expertise' and other resources.

In many instances the librarian will collaborate with other stakeholders like 'communities of practice' and non governmental organizations and even government agencies which might be endowed with resources or contacts that the library may not poses. In a number of cases the librarian will simply provides the venue and coordinate activities while regularly checking on feedback to ensure that maximum impact is derived from the services provided.

And so it is that the organization of a public library, its resources and services will be informed by these expressed needs paying particular attention to creation of a welcoming environment to the local community.

The hallmark of a successful information service is sensitivity and greater responsiveness to what the target community wants and desires. A need-based approach, receptive to the aspirations and information seeking behaviours of local communities, anchored on relationship building and networking, pro- 
vides the framework of a 'service level agreement' between the library and the community.

\subsection{Concluding remarks}

The general performance of public libraries in Africa has not advanced far enough to galvanise a sense of pride to the profession. Cosmetic changes, alternative or parallel services have given new meaning to the image of libraries but have yielded short-lived or negligible benefits to the masses of the disadvantaged populations.

It seems unlikely that Africa will attain the MDGs, in the given time period, for various reasons outside the scope of this paper. However, Africa is granted yet another window of opportunity to transform public libraries to the extent that they can play a meaningful role in fighting poverty.

Scarcity of resources in Africa, and common sense, do no warrant new investments to establish functional libraries. What is envisaged is taking radical steps to transform existing building and services into practical libraries for Africa. It is very important that 'new public libraries' operate within the framework of public funding for sustenance.

\section{References}

Alemna, A. 1995. Community libraries: an alternative to public libraries in Africa. Library Review, March. (Online). Available http://proquest.umi.com/ pqdweb? index $=1 \&$ did $=117540160 \&$ SrchMode $=3 \&$ sid $=1 \&$ Fmt $=2 \&$ VInst $=$ PRO D\&VType $=$ PQD\&RQT $=309 \&$ VName $=$ PQD \&TS $=1205575007 \&$ clientId $=5712$ 5\&aid=1 (Accessed 15 March 2008.

Akst, D. 2005. Do libraries matter? Carnegie Reporter (Online). Available http:// www.carnegie.org/report/10/books/index.html (Accessed 12 March 2008).

Brain, C. 2005. "In" versus "with" the community: Using a community approach to public library services. Feliciter, 51 (6):271-273.

Darla, M. at. al. 2005. Community development libraries: starting out. Felicity, $51(6): 265-267$.

Dent, V. \& Yannotta, L. 2005. A rural community library in Africa: A study of its use and users. Libri, 55:39-55. 
Hart, G. 2007. Social capital; a fresh vision for public libraries in South Africa? South African Journal of Libraries and Information Science, 73(1):14-24.

IFLA. 2004. IFLA/UNESCO public library manifesto 1994. (Online). Available: http://www.ifla.org/VII/s8/unesco/eng.htm (Accessed 19 April 2008).

Issak, A. 2002. Public Libraries in Africa: A report and annotated bibliography. London: INASP.

Kabamba, J. 1999. Speak out and reach out with a difference: Advocacy in the information age: Paper presented at the Library and Information Association of South Africa (LIASA) conference. $21^{\text {st }}-23^{\text {rd }}$ September 1999, Cape Town, South Africa.

Lor, P. Helden, P \& Bothma, T. 2005. Developing a GIS-based inventory of South Africa's public libraries: The public and community libraries inventory of South Africa. South Africa journal of Library \& Information Science, 71(3):268274.

Mchombu, K. An investigation into the information needs for poverty eradication at Greenwell Matongo in Katulura, Windhoek, in the context of the millennium development Goals (MDG): Paper presented at the World Libraries and Information Congress. $73^{\text {rd }}$ IFLA General Conference and Council, $19^{\text {th }}-23^{\text {rd }}$ August 2007, Durban, South Africa.

Mostert, B. 2001. African public library systems: A literature survey. LIBRES, March. (Online). Available http://libres.curtin.edu.au/libres11n1/mostert.htm (Accessed 15 March 2008).

Mostert, B. \& Vermeulen, W. 1998. Community libraries: The concept and its application by the Pinetown Public Library. South Africa Journal of Library \& Information Science, March. (Online). Available http://web.ebscohost.com/ehost/ detail? vid=28\&hid=102\&sid=63f8771a-bcc3-4be8-8f2a-f6ef7cbc761d $\% 40$ session mgr108 (accessed 16 March 2008).

Ocholla, D. 2006. Information accessibility by the marginalized in South Africa and the role of libraries. In The IFLA/FAIFE theme report 2006: Libraries and the fight against HIV/AIDS. Poverty and corruption. (Online). Available http:// 
www.lis.uzulu.ac.za/2006/Ocholla\%20Faife\%20ifla\%202006\%20October\%202 006\%206th.pdf (Accessed 16 March 2008).

Snyman, M. \& Snyman, R. 2003. Getting information to disadvantaged rural communities: the centre approach. South African Journal of library \& Information Science, 69(2):95-106.

UN. 2007.The Millennium Development Goals Report 2007. New York: United Nartions.

UNDP. 2007/2008. Human development reports: Human development concept (Online). Available http://hdr.undp.org/en/humandev/ (Accessed 14 March 2008).

World Bank. 1999. Knowledge for development (Online). Available http://go. worldbank.org/MPUHAJOPF0 (Accessed March 15 2008). 